\title{
IMPROVEMENT OF THERMAL ESTIMATION AT LAND COVER BOUNDARY BY USING QUANTILE
}

\author{
Tsukasa Hosomura \\ Division of Information System Design, School of Science and Engineering, \\ Tokyo Denki University, Hatoyama, Hiki, Saitama, 350-0394, Japan \\ hosomura@mail.dendai.ac.jp
}

\section{Commission VIII/8}

KEY WORDS: Statistics, High Resolution, Classification, Infrared, Accuracy Analysis, Urban, Data Analysis

\begin{abstract}
:
Land cover classification was conducted for Landsat ETM image of Urmqi. Maximum likelihood classification algorism was used for this purpose. Classification classes were urban, water body, forest, soil, bare ground1, bare ground2, vegetation1, vegetation2 and vegetation3. Mask image of each land cover was created from the obtained classification image. Thermal band image of each land cover was extracted by using the mask image. In general, mean value and standard deviation are calculated for the thermal band image. However, these values were affected by the difference of ground resolution. In this study, we introduced quantiles to avoid this problem. Quantiles are points taken at regular intervals from the cumulative distribution function. Quantiles showed the effectiveness of decreasing the error caused from the difference of ground resolution.
\end{abstract}

\section{INTRODUCTION}

The air temperature at the city center is higher than that of the surrounding non-urban areas so that it looks like an island. This phenomenon is so called "Urban Heat Island". In early days, it has attracted attentions as an environmental problem unique to urban area. The investigation area of Urmqi, which is the regional capital of Xinjiang Uyghr Autonomous Region in the dry northwestern part of China, has gained rapid development in recent decades. Together with economic development, the landscape has changed significantly. Land use/cover change has significant impacts on regional environment. Land surface temperature is an important indicator for assessment of regional environment especially in big cities such as Urumqi where urban heat island can usually be relatively obvious.

In this study we aim at specifying the urban expansion characteristics of Urmqi City using Landsat ETM images to detect and evaluate the land use and land cover change and analyze the relationship between land use and heat environment of Urmqi city.

Land cover classification was conducted for Landsat ETM image of Urmqi. Thermal band image of each land cover was extracted by using the mask image. In general, mean value and standard deviation are used for statistic analysis. However, difference of ground resolution between thermal infrared image and other band image influence these statistic variables. In this study, we introduced quantiles to avoid this problem.

\section{CONCEPT OF QUANTILE}

Quantiles are points taken at regular intervals from the cumulative distribution function. Quantiles showed the effectiveness of decreasing the error caused from the difference of ground resolution. The median is the central value of the distribution, such that half the points are less than or equal to it and half are larger than or equal to it. The quantiles divide the distribution into four equal parts, called fourths. The second quantile is the median. The interquartile range corresponds to the distance between the first quantile and the third quantile.

\section{THERMAL BAND DATA ANALYSIS}

In order to analyze relationship between land cover and heat 
island we have used maximum likelihood classification method. We calculated the statistic values of digital count number for the thermal image corresponding to each class.

\subsection{Image Classification}

We used maximum likelihood classification method in classifying the Landsat satellite image of the subject area Urmqi shown in Figure 1 and divided it into 9classes as of urban area, water body, forest, soil, bare ground1, bare ground2, vegetation1, vegetation2 and vegetation3 shown in Figure 2. Mask images were created from the classified image in order to calculate some statistical values. Mean value and standard deviation (S.D.) were calculated for the masked image. The obtained result is shown in Table 1. Median and interquartile range were also calculated. The obtained result is shown in Table 2 .

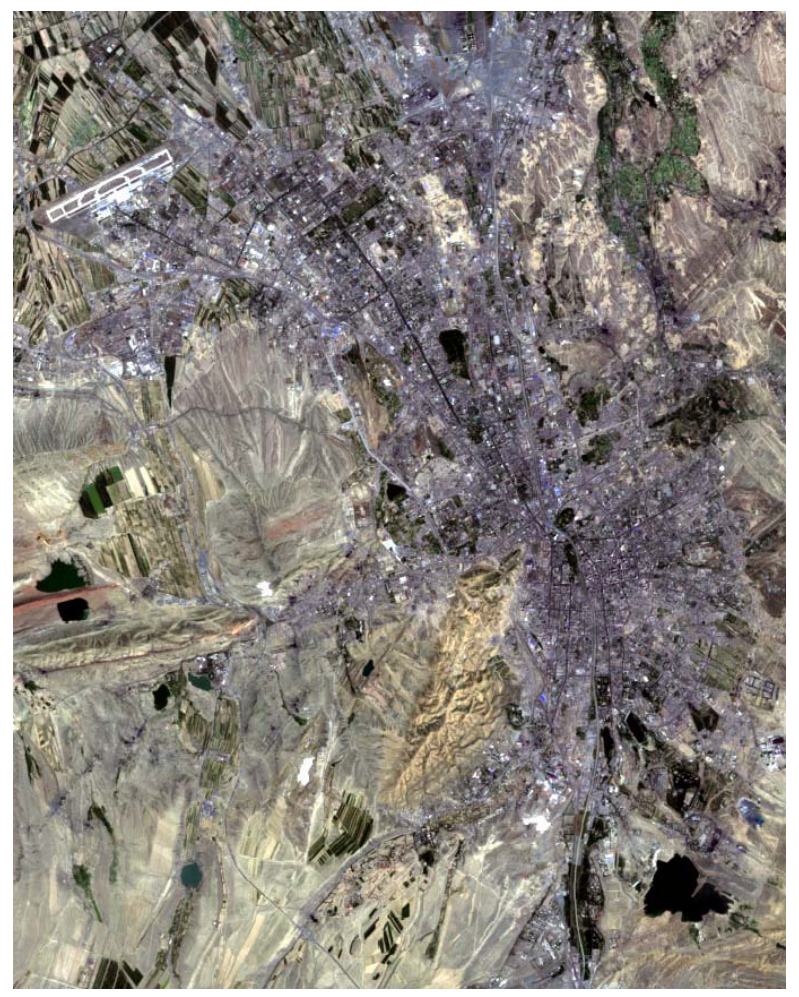

Figure 1 Landsat ETM image for Urmqi.

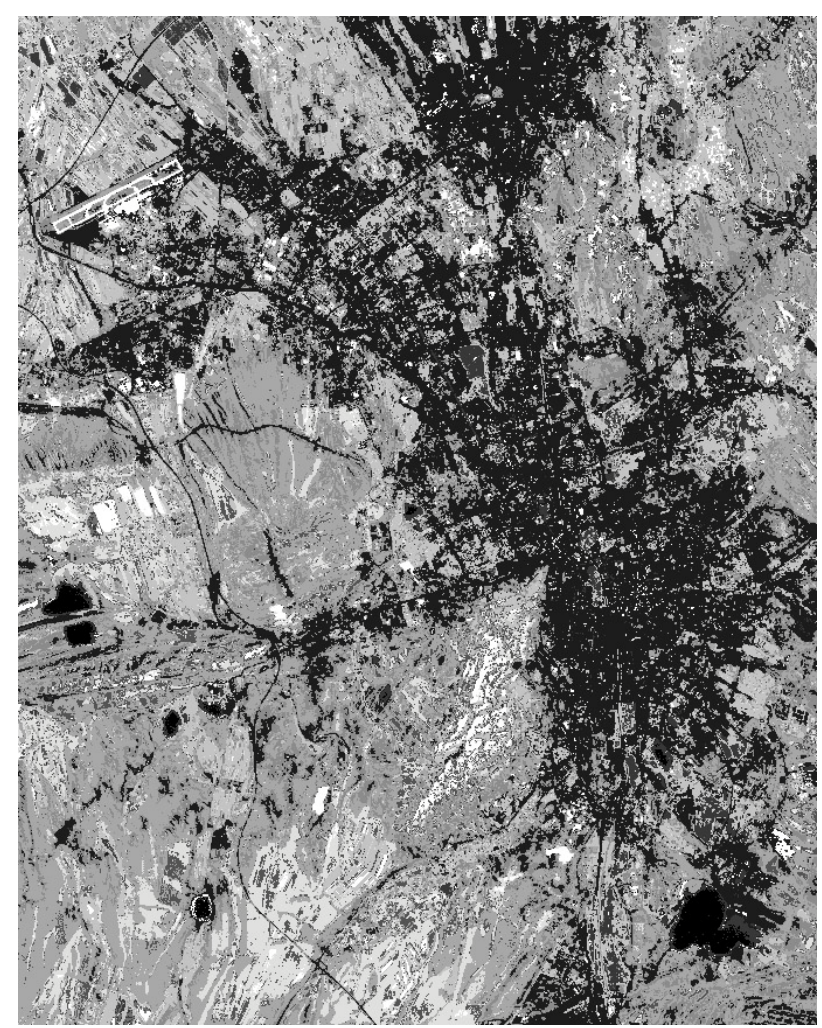

\begin{tabular}{|l|l|}
\hline & Urban \\
\hline Water body \\
\hline & Bare ground 1 \\
\hline Bare ground 2 \\
\hline Soil \\
\hline Forest \\
\hline Vegetation 1 \\
\hline & Vegetation 2 \\
\hline & Vegetation 3 \\
\hline
\end{tabular}

Figure 2 Classified image for target area. 


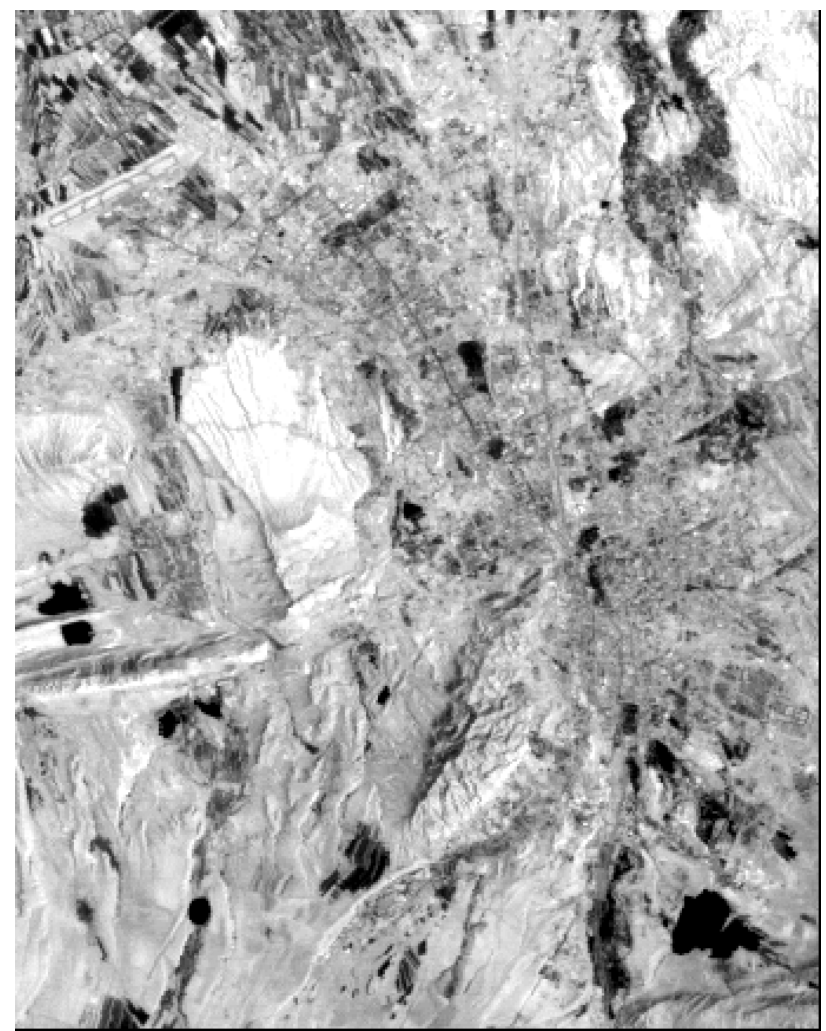

Figure 3 Thermal band image of Urmqi.

Based on the values of digital count number for the thermal image shown in Figure 3 corresponding to each class, We have seen that the temperature of urban area was higher than that of vegetation area.

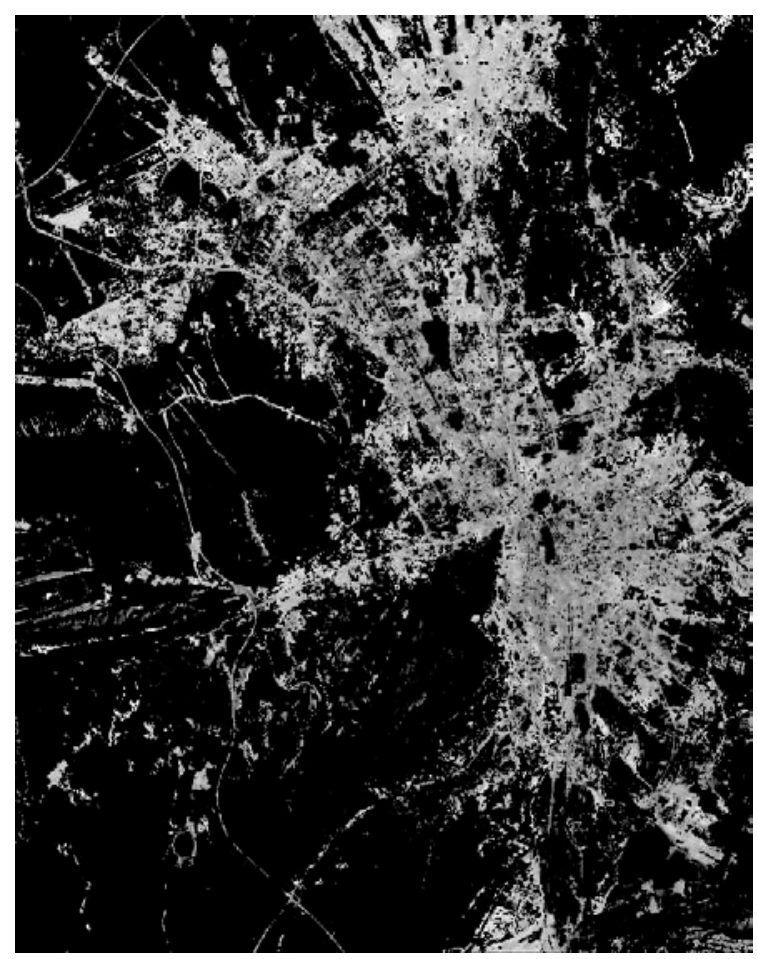

Figure 4 Mask image of urban area.

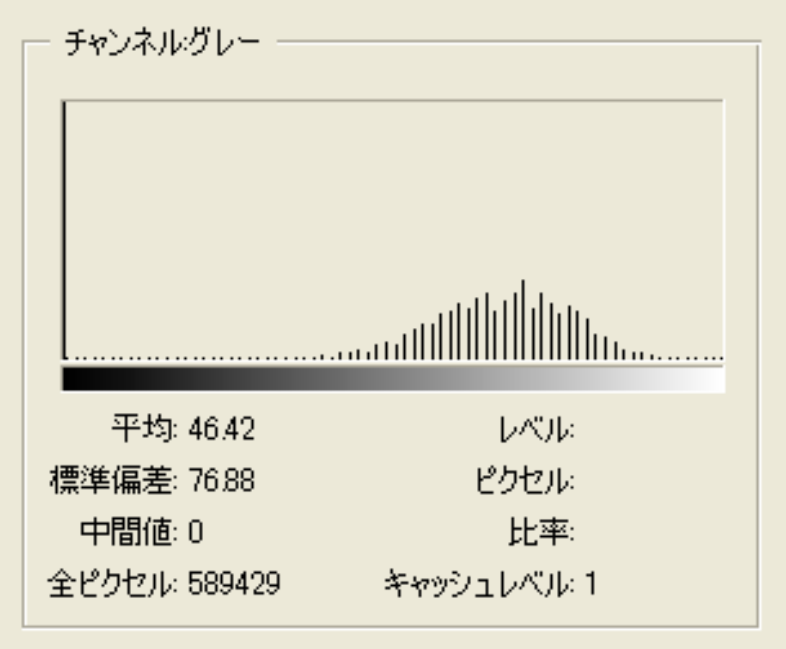

Figure 5 Histogram of urban area.

\begin{tabular}{|l|c|c|}
\hline & S.D. & $\begin{array}{c}\text { Mean } \\
\text { value }\end{array}$ \\
\hline Urban & 31.2 & 167.8 \\
\hline Water body & 34.9 & 36.8 \\
\hline Bare ground 1 & 35.0 & 170.3 \\
\hline Bare ground 2 & 33.2 & 182.0 \\
\hline Soil & 33.0 & 169.1 \\
\hline Forest & 42.5 & 126.9 \\
\hline Vegetation 1 & 36.7 & 72.2 \\
\hline Vegetation 2 & 34.8 & 119.1 \\
\hline Vegetation 3 & 30.9 & 179.3 \\
\hline
\end{tabular}

Table 1 Mean value and S.D. of thermal band data.

We can understand from the mean value on Table1 that the urban area temperature is higher than Vegetation area temperature. The high temperature of the urban area is mainly caused by the characteristic of urban surface. As cities and roads, buildings, and industrial areas, temperature in the city is relatively higher compared with their rural surroundings creating a heat island. In similar way, the temperature in other areas is also very high because of the strong bare soiled radiance. We can easily find out that the standard deviation values for forest area are very high because the forests have sunny sides as well as shadow sides. These sides temperatures fluctuate is considerably difference so the standard deviation values for forests area are very high.

The standard deviation value of water body is higher than 
estimated value. Pixel values of water body are very low and almost same. The standard deviation of water body should be low value. But obtain result shows large standard deviation value for water body. Such situation may be caused the boundary of water area which included other land cover. Ground resolution of thermal band image is $60 \mathrm{~m}$ $\mathrm{x} 60 \mathrm{~m}$. On the other hand ground resolution of other band images are $30 \mathrm{~m} \times 30 \mathrm{~m}$. Boundary of water body includes some other land cover pixels. The standard deviation was affected from these pixel values. In order to avoid such influence, we introduced quantiles. We used median and interquartile range instead of mean value and standard deviation.

\begin{tabular}{|l|c|c|}
\hline & $\begin{array}{c}\text { Interquartile } \\
\text { range }\end{array}$ & Median \\
\hline Urban & 39 & $170-$ \\
\hline Water body & 50 & 20 \\
\hline Bare ground1 & 46 & 173 \\
\hline Bare ground2 & 39 & 183 \\
\hline Soil & 39 & 172 \\
\hline Forest & 57 & 130 \\
\hline Vegetation1 & 50 & 64 \\
\hline Vegetation2 & 47 & 120 \\
\hline Vegetation3 & 37 & 181 \\
\hline
\end{tabular}

Table 2 Median and interquartile range of thermal band data.

By comparing two tables, we could get the result which showed superiority of median and interquartile range for accurate thermal environment. Interquartile range is around twice of S.D.. Both median and interquartile range are less than mean value and twice of S.D. in water body.

\section{CONCLUSIONS}

Urmuqi was selected for the target city in this study. Land cover information was obtained from Landsat ETM image by using classification algorithm. Quantile was introduced for analyzing the thermal environment in the target area. Obtained result showed the potential of more accurate analysis by using quantile statistics.

\section{References}

[1] Imamu K., Hosomura, T, 2007. A Study On the
Interaction Between Urumqi Urban Land Use and Urban Heat Island Using Remote Sensing Data. ACRS 2007 The $28^{\text {th }}$ Asian Conference on Remote Sensing (12-16 November 2007) 